\title{
Effect of Different Carbon Materials as Electron Shuttles in the Anaerobic Biotransformation of Nitroanilines
}

\author{
Luciana Pereira, ${ }^{1}$ Raquel Pereira, ${ }^{1}$ Manuel F. R. Pereira, ${ }^{2}$ Madalena M. Alves ${ }^{1}$ \\ ${ }^{1} \mathrm{CEB}$-Centre of Biological Engineering, University of Minho, Braga, Portugal; \\ telephone: 351253601963; fax: +351 253604 429; e-mail: lucianapereira@deb.uminho.pt \\ ${ }^{2}$ Laboratório de Catálise e Materiais (LCM), Laboratório Associado LSRE/LCM, \\ Departamento de Engenharia Química, Faculdade Engenharia da Universidade do Porto, \\ Porto, Portugal
}

ABSTRACT: Aromatic amines resulted from azo dyes biotransformation under anaerobic conditions are generally recalcitrant to further anaerobic degradation. The catalytic effect of carbon materials (CM) on the reduction of azo dyes is known and has been confirmed in this work by increasing threefold the biological reduction rate of Mordant Yellow 1 (MY1). The resulting $m$-nitroaniline ( $m$-NoA) was further degraded to $m$-phenylenediamine ( $m$-Phe) only in the presence of $\mathrm{CM}$. The use of $\mathrm{CM}$ to degraded anaerobically aromatic amines resulted from azo dye reduction was never reported before. In the sequence, we studied the effect of different CM on the bioreduction of $o-, m$-, and $p$-NoA. Three microporous activated carbons with different surface chemistry, original $\left(\mathrm{AC}_{0}\right)$, chemical oxidized with $\mathrm{HNO}_{3}\left(\mathrm{AC}_{\mathrm{HNO}}\right)$, and thermal treated $\left(\mathrm{AC}_{\mathrm{H} 2}\right)$, and three mesoporous carbons, xerogels (CXA and $\mathrm{CXB}$ ) and nanotubes (CNT) were assessed. In the absence of $\mathrm{CM}$, NoA were only partially reduced to the corresponding Phe, whereas in the presence of $\mathrm{CM}$, more than $90 \%$ was converted to the corresponding Phe. $\mathrm{AC}_{\mathrm{H} 2}$ and $\mathrm{AC}_{0}$ were the best electron shuttles, increasing the rates up to eightfold. In $24 \mathrm{~h}$, the biological treatment of $\mathrm{NoA}$ and $\mathrm{MY} 1$ with $\mathrm{AC}_{0}$, decreased up to $88 \%$ the toxicity towards a methanogenic consortium, as compared to the non-treated solutions.

Biotechnol. Bioeng. 2016;113: 1194-1202.

(C) 2015 Wiley Periodicals, Inc.

KEYWORDS: anaerobic biological reduction; azo dyes; carbon materials; nitroanilines; redox mediator

Correspondence to: L. Pereira

Contract grant sponsor: FCT - Fundação para a Ciência e Technologia Strategic Contract grant number: UID/BIO/04469/2013

Contract grant sponsor: FCT - Fundação para a Ciência e Technologia Exploratory Contract grant number: EXPL/AAG-TEC/0898/2013

Received 5 September 2015; Revision received 17 November 2015; Accepted 22 November 2015

Accepted manuscript online 28 November 2015;

Article first published online 30 December 2015 in Wiley Online Library

(http://onlinelibrary.wiley.com/doi/10.1002/bit.25896/abstract).

DOI 10.1002/bit.25896

\section{Introduction}

Redox mediator (RM) compounds that can be reversibly oxidized and reduced, shuttling the electrons from a co-substrate to a target compounds to be degraded, act as catalysts in various reduction process, increasing the corresponding biotransformation rates (Van der Zee et al., 2001; Van der Zee and Cervantes, 2009). This is very important for the efficient start-up and operation of high-rate anaerobic reactors when treating effluents containing pollutants when the electron transfer rate can limit the overall process performance (Cervantes et al., 2001). CM have been shown as feasible RM for the microbial reduction of azo dyes (Amezquita-Garcia et al., 2013; Fu and Zhu, 2013; Gong et al., 2014; Mezohegyi et al., 2010; Pereira et al., 2010, 2014; Van der Zee et al., 2003; Wang et al., 2014; Yu et al., 2011). Because CM are insoluble, they can be easily immobilized inside the reactors, which is a clear advantage compared to soluble electron shuttles as for example anthraquinone-2, 6-disulfonate (AQDS). Furthermore, CM can be chemically and texturally modified in terms of surface area, pore size distribution, or by adding/removing chemical surface groups order to gain advantage for specific applications (Figueiredo et al., 1999; Pereira et al., 2010).

In the present study, the effect of $\mathrm{CM}$, including microporous $\mathrm{AC}_{0}, \mathrm{AC}_{\mathrm{HNO}}$ and $\mathrm{AC}_{\mathrm{H} 2}$, and mesoporous $\mathrm{CX}$ and $\mathrm{CNT}$, were studied as electron shuttles on the anaerobic biological reduction of the azo dye MY 1 and of the aromatic amines $o-, m$-, and $p$-NoA which can result from azo dye reduction under anaerobic conditions (Donlon et al., 1997; Garrigós et al., 2002; Sarasa et al., 1998). NoA are also commonly used in the industrial production of pharmaceuticals and synthetic dyes, originating contaminated wastewaters, and are categorized as toxic and mutagenic (Chung et al., 1997; Chung, 2000; Malca-Mor and Stark, 1982). They are also products of anaerobic reduction of explosives (Spain, 1995). The potential toxic effect of NoA, MY1, and of the respective treated solutions, was also evaluated for a methanogenic consortium degrading VFA.

Other authors have studied the catalytic effect of CM, such as AC (Gong et al., 2014), carbon black (Yu et al., 2011), and graphene (Fu and $\mathrm{Zhu}, 2013$ ), on chemical reduction of nitrobenzene and modified AC fibres on the chemical reduction of 4-nitrophenol and 
3-chloronitrobenzene (Amezquita-Garcia et al., 2013). Biological reduction of nitrocompounds was previously studied, but the catalytic effect of different $\mathrm{CM}$ on the biological reduction of NoA is investigated in this work for the first time.

\section{Experimental}

\section{Chemicals}

$o$-NoA (98\%), $m$-NoA (98\%), p-NoA (>99\%), MY1 (50\%), 5-ASA (>99\%), $m$-Phe (98\%), and $p$-Phe (98\%) were purchase from Sigma and used without additional purification. Chemical structures are illustrated in Figure 1. Chemicals used to prepare the macronutrients solution were purchase from Sigma-Aldrich or Fluka at highest analytic grade purity commercially available. Acetonitrile (ACN) for High Performance Liquid Chromatography (HPLC) analysis was purchased from Panreac at HPLC analytic grade. Resorcinol (99\%) and formaldehyde (37\%) were also purchased from Sigma-Aldrich (Enzymatic, Loures, Portugal).

\section{Preparation and Characterization of Carbon Materials}

CM used in this study were prepared as previously described (Carabineiro et al., 2011; Gonçalves et al., 2010; Orge et al., 2012; Pereira et al., 2010, 2014). Textural and chemical characteristics of the tested CM samples are summarized in SI and were published elsewhere (samples Figueiredo, 2013; Orge et al., 2012; Pereira et al., 2010, 2014; Tessonnier et al., 2009).

A commercial NoritROX0.8 AC was used as supplied by Norit (sample $\mathrm{AC}_{0}$ ). Two samples with different chemical surface composition maintaining the original textural properties as much as possible, were prepared from $\mathrm{AC}_{0}$ : (i) chemical oxidation of $\mathrm{AC}_{0}$ with $6 \mathrm{M}$ of $\mathrm{HNO}_{3}$ at boiling temperature for $3 \mathrm{~h}\left(\mathrm{AC}_{\mathrm{HNO} 3}\right)$ in order to produces $\mathrm{AC}$ samples with high content of acidic surface groups and (ii) starting from $\mathrm{AC}_{\mathrm{HNO} 3}, 1 \mathrm{~h}$ of thermal treatment under $\mathrm{H}_{2}$ flow at $700^{\circ} \mathrm{C}\left(\mathrm{AC}_{\mathrm{H}}\right)$, aiming to produce materials with low amount of oxygencontaining groups, and high basicity (Pereira et al., 2010). The synthesis of the CX consisted in the polycondensation of resorcinol with formaldehyde at an initially controlled $\mathrm{pH}$. In order to obtain a stable mesoporous structure, the $\mathrm{pH}$ of the synthesis may be fixed in between the $\mathrm{pH}$ range from 5.5 to 6.5. Larger pores are obtained at the lower $\mathrm{pH}$ limit (Figueiredo, 2013). In this study, samples were synthesized by the sol-gel process at pH 6.25 (CXA) and 5.45 (CXB) as described previously (Orge et al., 2012; Pereira et al., 2014).

The textural characterisation of $\mathrm{CM}$ was based on the corresponding $\mathrm{N}_{2}$ equilibrium adsorption/desorption isotherms, determined at $-196^{\circ} \mathrm{C}$ with a Quantachrome Instruments NOVA 4200e apparatus (Orge et al., 2012). BET surface areas $\left(\mathrm{S}_{\mathrm{BET}}\right)$, mesoporous surface areas $\left(\mathrm{S}_{\text {meso }}\right)$, micropore volumes $\left(\mathrm{V}_{\mu \text { pores }}\right)$, and average mesopore diameters were obtained by the BET method, the $t$ method and the Barret, Joyner and Halenda (BJH) method,<smiles>Nc1ccccc1[N+](=O)[O-]</smiles>

$o$-nitroaniline (o-NoA)<smiles>Nc1cccc(N)c1</smiles>

$m$-phenylenediamine ( $m$-Phe)<smiles>Nc1cccc([N+](=O)[O-])c1</smiles>

$m$-nitroaniline (m-NoA)<smiles>Nc1ccc(N)cc1</smiles>

$p$-phenylenediamine (p-Phe)<smiles>Nc1ccc([N+](=O)[O-])cc1</smiles>

$p$-nitroaniline $(p-\mathrm{NoA})$<smiles>Nc1ccc(O)c(C(=O)O)c1</smiles>
(5-ASA)<smiles>O=C(O[Na])c1cc(N=Nc2cccc([N+](=O)[O-])c2)ccc1O</smiles>

Figure 1. Molecular structure of the aromatic amines, $o-, m-$, and $p$-NoA, $m$-and $p$-Phe, 5-ASA, and of the azo dye MY10. 
respectively. The $\mathrm{pH}$ of point zero charge $\left(\mathrm{pH}_{\mathrm{pzc}}\right)$ determines quantitatively the net charge (positive or negative) on the $\mathrm{CM}$ surface as a function of the $\mathrm{pH}$ of the solution. It was determined as follows: $50 \mathrm{~cm}^{3}$ of a $0.01 \mathrm{M} \mathrm{NaCl}$ solution was placed in a closed Erlenmeyer flask and the $\mathrm{pH}$ was adjusted to a value between 2 and 12 with the solutions $0.1 \mathrm{M} \mathrm{HCl}$ or $0.1 \mathrm{M} \mathrm{NaOH}$. Then, $0.15 \mathrm{~g}$ of each CM sample was added and the final $\mathrm{pH}$ measured after $48 \mathrm{~h}$ under agitation at room temperature. The $\mathrm{pH}_{\mathrm{pzc}}$ is the point where the curve $\mathrm{pH}_{\text {final }}$ versus $\mathrm{pH}_{\text {initial }}$ crosses the line $\mathrm{pH}_{\text {initial }}=$ $\mathrm{pH}_{\text {final }}$. In order to characterize the surface groups of $\mathrm{AC}$ samples, $\mathrm{CO} / \mathrm{CO}_{2}$ release was done by temperature-programmed desorption (TPD) are described by (Figueiredo et al., 1999). Briefly, at low temperatures the $\mathrm{CO}_{2}$ spectrum is decomposed to the corresponding carboxylic acids, at intermediate temperatures to the carboxylic anhydrides, and at high temperatures to lactones. The CO spectrum gives information of the presence of phenols, at intermediate temperatures, and carbonyl/quinones, at high temperatures. The carboxylic anhydrides decompose by releasing one $\mathrm{CO}$ and one $\mathrm{CO}_{2}$ molecule. Thus, a peak of the same shape and equal magnitude to that found on the $\mathrm{CO}_{2}$ spectrum was included in $\mathrm{CO}$ spectrum. This peak was pre-defined from the deconvolution of the $\mathrm{CO}_{2}$ spectrum.

A commercial CNT sample (Nanocyl 3100) was also tested. According to the supplier, it has an average diameter of $9.5 \mathrm{~nm}$, an average length of $1.5 \mu \mathrm{m}$, and carbon purity higher than $95 \%$.

\section{Biological Assays}

Biological reduction of MY1 and NoA was conducted in $70 \mathrm{~mL}$ serum bottles, sealed with a butyl rubber stopper, containing $25 \mathrm{~mL}$ of medium. The primary electron donating substrate was composed of $2 \mathrm{~g} \mathrm{~L}^{-1}$ chemical oxygen demand (COD) of a $\mathrm{NaOH}$-neutralised VFA mixture, containing acetate, propionate and butyrate in a COD based ratio of 1:10:10. Basal nutrients were $\left(\mathrm{g} \mathrm{L}^{-1}\right)$ : $\mathrm{NH}_{4} \mathrm{Cl}(2.8)$, $\mathrm{CaCl}_{2}$ (0.06), $\mathrm{KH}_{2} \mathrm{PO}_{4}(2.5), \mathrm{MgSO}_{4}$, and $7 \mathrm{H}_{2} \mathrm{O}$ (1.0). Medium was buffered at a pH of $7.3 \pm 0.2$ with $\mathrm{NaHCO}_{3}\left(2.5 \mathrm{~g} \mathrm{~L}^{-1}\right)$. Anaerobic granular sludge, collected from an anaerobic internal circulation reactor of a brewery wastewater treatment plant, was the inoculum at a concentration of $(2.5 \pm 0.5) \mathrm{g} \mathrm{L}^{-1}$ volatile suspended solids (VSS). MY1 and NoA were added at the final concentration of $1 \mathrm{mmol} \mathrm{L}^{-1}$. The effect of the different $\mathrm{CM}\left(\mathrm{AC}_{0}, \mathrm{AC}_{\mathrm{H} 2}, \mathrm{AC}_{\mathrm{HNO} 3}\right.$, CXA, CXB, CNT) on biological reduction of MY1 and NoA was tested at a concentration of $\mathrm{CM}$ of $0.1 \mathrm{~g} \mathrm{~L}^{-1}$. This concentration is in accordance with a previous work of our research team (Pereira et al., 2010), in which $\mathrm{AC}$ concentrations from 0.1 to $0.6 \mathrm{~g} \mathrm{~L}^{-1}$ were tested and led to an increase of the dye adsorption (from less than $10 \%$ to $65 \%$, as observed in abiotic assays), but the reduction rate and final extent in the biological assays was similar at all the concentrations tested. These results are important once AC is costly and, therefore, the use of low amounts is an advantage for biological processes application. Furthermore, as a RM, CM are recycled from its oxidized and reduced state and should be effective at low concentrations. Sludge was incubated overnight at $37^{\circ} \mathrm{C}$ in a rotary shaker at $120 \mathrm{rpm}$. After the pre-incubation period, the compounds to be tested and VFÁs $\left(2 \mathrm{gL}^{-1}\right.$ of COD) were added with a syringe from the stock solution to the desired concentration. Controls include biological assays without $\mathrm{CM}$ and abiotic assays with $\mathrm{CM}$.
Blank assays containing only the tested compounds (NoA or MY1) in basal medium, were also conducted. All experiments were prepared in triplicate. The reactions were monitored during $48 \mathrm{~h}$ for MY1 and during $24 \mathrm{~h}$ for NoA by spectroscopy and HPLC.

\section{CM as Electron Shuttle}

In order to assess the capacity of $\mathrm{CM}$ to accept electrons from the biological oxidation of VFA, similar assays were conducted, with 0.1 and $1.0 \mathrm{~g} \mathrm{~L}^{-1}$ of $\mathrm{AC}_{0}$, without NoA or MY1. A set of controls excluding either biomass, or $\mathrm{AC}_{0}$, or VFA was incorporated. To prevent the flow of electrons to methanogens, the cultures were supplemented with $20 \mathrm{mmol} \mathrm{L}^{-1}$ of 2-bromoethanesulfonate (BES). After $24 \mathrm{~h}$ incubation, $\mathrm{AC}_{0}$ was removed from the medium in an anaerobic chamber, and incubated with a solution of $1 \mathrm{mmol} \mathrm{L}^{-1}$ $\mathrm{Fe}^{3+}$. The electron transfer from $\mathrm{AC}_{0}$ to $\mathrm{Fe}^{3+}$, reducing it to $\mathrm{Fe}^{2+}$, was measured by the ferrozine method (Lovely and Phillips, 1986). Briefly, this technique is based in the reaction of $\mathrm{Fe}^{2+}$ reaction with ferrozine (monosodium salt hydrate of 3-(2-pyridyl)-5,6diphenyl-1,2,4-triazine-p, $\mathrm{p}^{\prime}$-disulfonic acid), forming a stable magenta complex with a maximum absorbance at $562 \mathrm{~nm}$ $\left(\mathrm{Abs}_{562}\right)$. The concentration of $\mathrm{Fe}^{2+}\left(\mathrm{C}_{\mathrm{Fe} 2+}\right)$ was calculated with the calibration curve: $\mathrm{Abs}_{562}=8.64{ }^{*} \mathrm{C}_{\mathrm{Fe} 2+}-0.311$ for Abs $>1$ and $\mathrm{Abs}_{562}=10.98^{*} \mathrm{C}_{\mathrm{Fe} 2+}+0.038$ for $\mathrm{Abs}<0.1$.

\section{Methanogenic Toxicity Assays of MY1, NoA, 5-ASA, and of the Final Treated Solutions}

Methanogenic toxicity assays were performed by measuring the specific methanogenic activity (SMA) with VFA as substrate (NaOH-neutralised VFA mixture, containing acetate, propionate and butyrate in a COD based ratio of 1:10:10), in the presence of the selected toxicant. The selected toxicants were NoA and MY1, tested in the range of 0.125 to $1 \mathrm{mmol} \mathrm{L}^{-1}, 5$-ASA at concentrations between 0.2 and $4 \mathrm{mmol} \mathrm{L}^{-1}$, and the treated solutions (TS), obtained after the treatment of $1 \mathrm{mmol} \mathrm{L}^{-1}$ of NoA and MY1, in the presence of $\mathrm{AC}_{0}$. SMA tests were performed in serum bottles of $25 \mathrm{~mL}$, containing $12.5 \mathrm{~mL}$ of buffer solution with $3.05 \mathrm{~g} \mathrm{~L}^{-1}$ sodium bicarbonate and $1 \mathrm{~g} \mathrm{~L}^{-1}$ of Resazurin. Anaerobic granular sludge was used as inoculum at a final concentration of $(2.1 \pm 0.2) \mathrm{g}$ $\mathrm{L}^{-1}$ of volatile suspended solids (VSS). The SMA of the granular sludge in the presence of the VFA solution was similar for all the assays $\left(0.4 \pm 0.1 \mathrm{~g} \mathrm{COD}^{-\mathrm{CH}_{4}} \mathrm{gVSS}^{-1} \mathrm{~d}^{-1}\right)$. The headspace was flushed with a mixture of $\mathrm{N}_{2} / \mathrm{CO}_{2}(80 / 20 \mathrm{vol} / \mathrm{vol})$. The final $\mathrm{pH}$ was $7.2 \pm 0.2$. Following the addition of $0.125 \mathrm{~mol} \mathrm{~L}^{-1} \mathrm{Na}_{2} \mathrm{~S}$, under strict anaerobic conditions, the vials were incubated overnight at $37^{\circ} \mathrm{C}$ and $120 \mathrm{rpm}$. After that period, the mixture of VFA and the solutions to be tested were added and the vials were maintained at $37^{\circ} \mathrm{C}$ and $120 \mathrm{rpm}$ during the entire assay. The pressure was measured every $60 \mathrm{~min}$ by using a hand-held pressure transducer able of measuring a pressure variation of $\pm 202.6 \mathrm{kPa}(0-202.6 \mathrm{kPa})$ with a minimum detectable variation of $0.5 \mathrm{kPa}$, corresponding to $0.05 \mathrm{~mL}$ of biogas in a $10 \mathrm{~mL}$ headspace. The assay was finished when the pressure remained stable. A totol of $500 \mu \mathrm{L}$ of sample volume were collected periodically, using a gas-tight syringe and methane content of the biogas was measured by gas chromatography using a Chrompack Haysep Q (80-100 mesh) column (Chrompack, Les Ulis, France), with $\mathrm{N}_{2}$ as carrier gas at $30 \mathrm{~mL}$ 
$\min ^{-1}$, and a flame-ionization detector. Temperatures of the injection port, column, and flame-ionization detector were 110,35 , and $220^{\circ} \mathrm{C}$, respectively. The values of methane production were corrected for the standard temperature and pressure conditions (STP). In order to determine the activities, the values of pressure (calibrated as an analogical signal in $\mathrm{mV}$ ) were plotted as a function of time and the initial slopes of the methane production were calculated. SMA values were determined dividing the initial slope by the VSS content of each vial at the end of the experiment and were expressed in $\mathrm{g}$ of $\mathrm{CH}_{4}$ per $\mathrm{g}$ of VSS per day. Two controls were made in the same conditions, one containing only VFAs (control assay) and the other without any substrate or toxicant (blank assay) that was used to subtract the background methane production. All batch experiments were performed in triplicate. The effect of tested toxicants was evaluated by calculating the relative reduction of the SMA in comparison with the control assay, expressed as percentage of activity.

\section{Analytical Techniques}

Reactions were monitored spectrophotometricaly in a 96-well plate reader (ELISA BIO-TEK, Izasa) and by HPLC. At select intervals, samples were withdrawn $(300 \mu \mathrm{L})$, centrifuged at $5000 \mathrm{rpm}$ for $10 \mathrm{~min}$ to remove the biomass and/or CM, and diluted to obtain samples with an absorbance below the detection limit, 3.0. The UV-vis spectra $(200-800 \mathrm{~nm})$ were recorded and NoA concentration calculated at $\lambda_{\max }$ with the molar extinction coefficients $\left(\lambda_{\max }: \varepsilon_{410 \mathrm{~nm}}=1.345 \mathrm{~L} \mathrm{mmol}^{-1}\right.$ $\mathrm{cm}^{-1}$ for $o$-NoA; $\varepsilon_{350 \mathrm{~nm}}=0.582 \mathrm{~L} \mathrm{mmol}^{-1} \mathrm{~cm}^{-1}$ for $m$-NoA; $\varepsilon_{380 \mathrm{~nm}}=3.104 \mathrm{~L} \mathrm{mmol}^{-1} \mathrm{~cm}^{-1}$ for $p$-NoA; and $\varepsilon_{350 \mathrm{~nm}}=0.582$ $\mathrm{L} \mathrm{mmol}_{-1} \mathrm{~cm}^{-1}$ for MY1). First-order reduction rate constants were calculated in OriginPro 6.1 software, applying the equation $\mathrm{Ct}=\mathrm{C}_{0}+\mathrm{C}_{\mathrm{i}} \mathrm{e}^{-\mathrm{kt}}$, where $\mathrm{C}_{\mathrm{t}}$ is the concentration at time $t ; \mathrm{C}_{0}$, the offset; $C_{i}$, the concentration at time initial time; $k$, the first-order rate constant $\left(\mathrm{h}^{-1}\right)$.

HPLC analyses were performed in a HPLC (JASCOAS-2057 Plus) equipped with a Diode Array Detector. A C18 reverse phase Nucleodur MNC18 column $(250 \times 9 \times 4.0 \mathrm{~mm}, 5 \mu \mathrm{M}$ particle size, and pore of $100 \AA$ from Machenerey-Nagel, Switzerland) was used. Mobile phase was composed of the solvents: A, ultrapure water and B, Acetonitrile. Compounds were eluted at a flow rate of $0.5 \mathrm{~mL} \mathrm{~min}^{-1}$ and at room temperature, with isocratic condition containing $50 \%$ of $\mathrm{A}$ and $50 \%$ of $\mathrm{B}$, during $20 \mathrm{~min}$. Compounds elution was monitored at $\lambda_{\max }$ of compounds and at $230 \mathrm{~nm}$ for reduction products. The retention times, Rt, of NoA and products are available at supplementary information, SI, (Table SI).

\section{Results and Discussion}

\section{CM as Redox Mediators on MY1 Biological Reduction}

Biological reduction of MY1 was assessed by UV-visible spectroscopy and by HPLC. MY1 was totally decolourised in $24 \mathrm{~h}$ when $\mathrm{CM}$ were present in the reaction medium, while in its absence only $70 \%$ of decolourisation was reached (Fig. $2 \mathrm{~A}$ and B). The rate of decolourization was also higher, up to threefold, in the presence of CM. In the first $24 \mathrm{~h}$, a decrease of the HPLC peak corresponding to the dye ( $R t$ of $4.6 \mathrm{~min}$ ) was observed with the formation of two new peaks at $R t$ of 3.8 and $10 \mathrm{~min}$ (Fig. 2A). As comparing with the
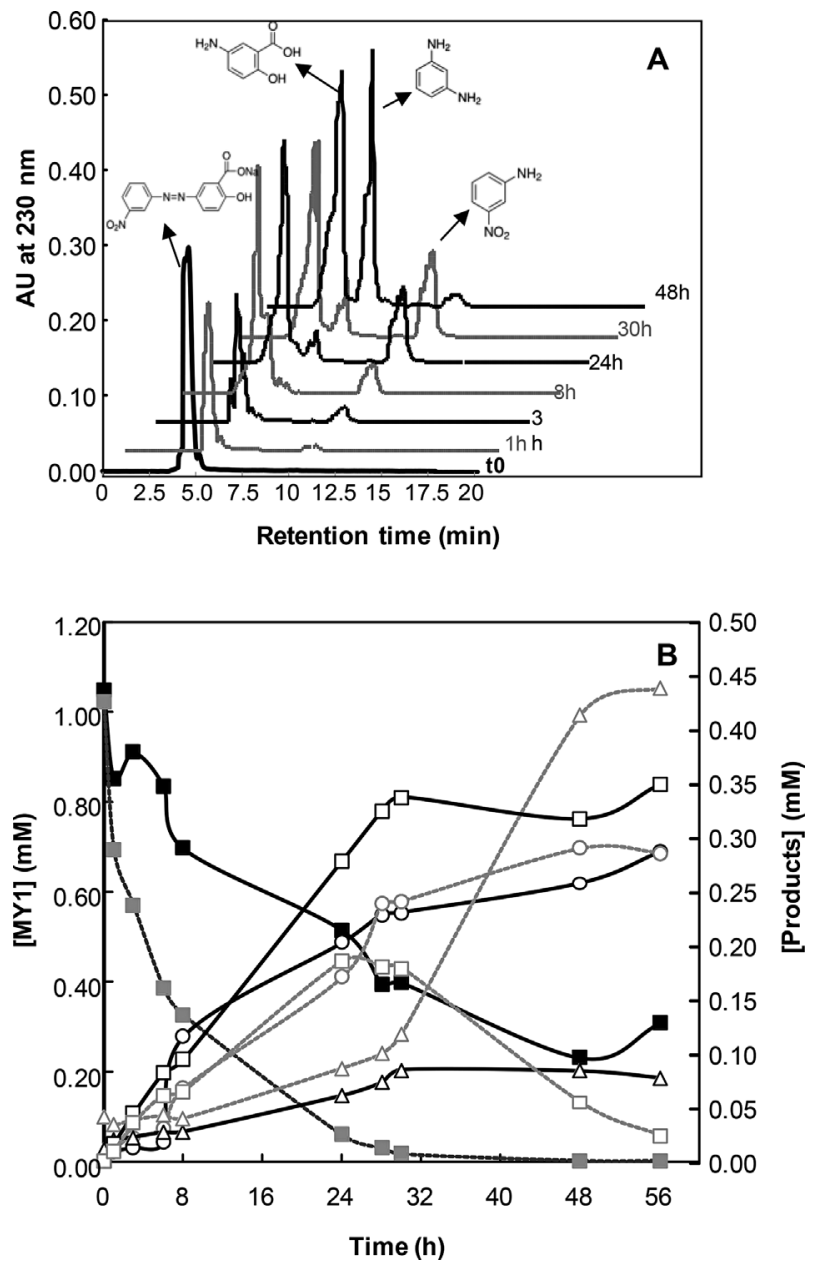

Figure 2. HPLC chromatograms of MY1 biological reduction at $230 \mathrm{~nm}(\mathbf{A})$ and areas of dye biological reduction, and products formed, within $48 \mathrm{~h}$ of reaction (B). $\circ, 5$ ASA; $\square$, MY1; $\Delta, m$-Phe; $\square, m$-NoA. Black symbols correspond to the reaction in the absence of $A C_{0}$ and gray to the reaction in the presence of $A C_{0}$. Rcontrol $=0.057$ $\pm 0.015 \mathrm{~h}^{-1}$ and $\mathrm{rAC}_{0}=0.161 \pm 0.013 \mathrm{~h}^{-1}$.

standards, those two peaks correspond to the aromatic amines, 5ASA and $m$-NoA. Interestingly, in the presence of $\mathrm{CM}, m$-NoA was further reduced to $m$-phe (Rt $5.1 \mathrm{~min}$ ), although 5-ASA was recalcitrant during the entire incubation period, $48 \mathrm{~h}$ (Table SI). Biological reduction assays of 5-ASA in the same conditions as for MY1, confirm its recalcitrant nature within $48 \mathrm{~h}$ of reaction (data not shown). Donlon et al. (1997) have also proposed the mechanism of biological reduction of Mordant Orange 1 (MO1), a similar azo dye, by a granular sludge in UASB reactors, with the formation of the correspondent aromatic amines 5-ASA, and $p$-Phe. However, in their study, for an effective reduction of MO1 to occur, the dye had to be firstly added at subtoxic concentration $\left(0.01 \mathrm{mmol} \mathrm{L}^{-1}\right)$ and then increased up to $0.35 \mathrm{mmol} \mathrm{L}^{-1}$. Authors have also obtained total mineralization of 5-ASA by methanogenic consortia in continuous reactor, but only after prolonged operation for several months. Likewise, Razo-Flores et al. (1999) concluded that 5-ASA degradation required a long period of sludge acclimation in UASB bioreactors, even for concentrations as low as $0.5 \mathrm{mmol} \mathrm{L}^{-1}$. 
CM may increase the rate of electrons transfer but may also affect the metabolic pathways in anaerobic microbial processes by promoting direct electron transfer, rather than via hydrogen or formate. It has been suggested that the presence of conductive materials such as haematite, magnetite, and granular AC may have a pivotal role in the effectivity of electron transfer processes in anaerobic microbial communities (Kato et al., 2012; Liu et al., 2012) in part by promoting the growth of electrogens able to perform DIET. Recent studies have shown that in the absence of electrodes, magnetite stimulated methane production in the rice paddy sediments, with an enrichment of Geobacter species (Kato et al., 2012). The authors speculated that, in the presence of magnetite, Geobacter species donate electrons to methanogens belonging to the genus Methanosarcina, leading to an enrichment of these species. Also another study suggested that amendments of granular activated carbon could accelerate the initiation of methanogenesis in a reactor start up (Liu et al., 2012).

\section{CM as Redox Mediators on NoA Bioreduction}

Previous studies have concluded that biodegradation of NoA under anaerobic conditions is a slow process requiring biomass acclimation, and occurs via reduction of the nitro group, forming nitroso and hydroxylamino intermediates to the corresponding amines, through a six-electron transfer mechanism (Donlon et al., 1997).

Investigating the effect of $\mathrm{CM}$ on $\mathrm{MY} 1$ reduction, we have observed that in the presence of $\mathrm{CM}$, the corresponding NoA formed from azo link break, could be further reduced. So, the effect of different $\mathrm{CM}$, acting as RM in order to accelerate the anaerobic bioreduction of structurally related NoA, was studied and compared in the present study. During the reaction, the yellow color decreased and, in the presence of $\mathrm{CM}$, the solution turned colorless in $\sim 3 \mathrm{~h}$. As

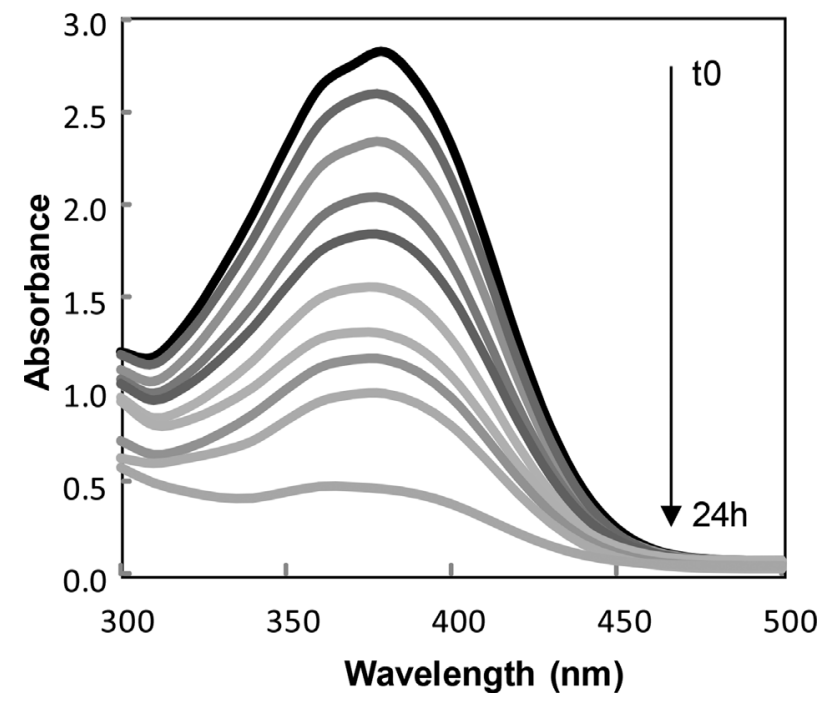

Figure 3. Biological reduction of $p-N_{0} A$ in the presence of $A C_{0}$ as monitored by UV-vis spectroscopy. monitored by spectrophotometry, a decrease of the visible spectra was observed (Fig. 3). NoA biotransformation was also monitored by HPLC with DAD detector. A decrease of the NoA peak was observed at the maximum wavelength of the NoA (Fig. 4A). At $230 \mathrm{~nm}$, both NoA removal and Phe formation could be monitored (Fig. 4B). In the experiments without $\mathrm{CM}$, the percentages of biological reduction in the equilibrium $(\sim 24 \mathrm{~h})$ were $32 \%, 56 \%$, and $52 \%$, for $o-, m$-, and $p$-NoA, respectively. Conversely, reduction percentages higher than $90 \%$ were obtained for all NoA, in the presence of all CM tested, irrespectively of its specific characteristics. They are in the reaction at very little concentration $\left(0.1 \mathrm{~g} \mathrm{~L}^{-1}\right)$, being effective at that concentration, because the process of shuttling the electrons implies that $\mathrm{CM}$ they can be reversibly oxidized and reduced, as long as an electron donor (substrate) is available. The tiny amount of CM used limits its role as a support material or adsorbent, as proven in the abiotic control assays (Fig. 5). Moreover, no reduction was observed in the blank assay, indicating the stability of the tested compounds in the basal medium.

The kinetics of NoA reduction followed a first-order. Reduction rates were, in general, higher for $m$-NoA than for $p$-NoA and $o$-NoA (Fig. 5, Table I), suggesting a effect of the substituent position. Jbarah and Holze (2006), studying the redox electrochemistry of $o-, m$-, and $p$-NoA have stated that $m$-NoA is reduced more easily (at less negative potentials) than both $o$-NoA and $p$-NoA, explained by the lower electron density of nitro-group at the metha position. The microporous $\mathrm{CM} \mathrm{AC}_{0}$ and $\mathrm{AC}_{\mathrm{H} 2}$ led to three, four, and eightfold increase of the reduction rates for $o^{-}, m-$, and $p$-NoA, respectively, as compared with the reaction in the absence of $\mathrm{CM}$ (Table I). In previous results with azo dyes (Pereira et al., 2014), better performance was achieved with the mesoporous CNT and CX, probably because the pore size of microporous materials does not allow the access of dyes. NoA are smaller molecules and the better results herein obtained, might be related with the easier access to the higher available surface area of the microporous CM. Similarly to the known AQDS, the effect as RM of AC has been attributed to the presence of quinone groups on its surface (Van der Zee et al., 2003). However, in this study, comparing among the three samples of microporous $\mathrm{AC}$, better results were obtained with $\mathrm{AC}_{0}$ and $\mathrm{AC}_{\mathrm{H} 2}$ than with the $\mathrm{AC}_{\mathrm{HNO} 3}$ sample that presents a higher amount of quinone groups. In fact, in spite of the higher amount of quinone groups in $\mathrm{AC}_{\mathrm{HNO} 3}$ compared to the other samples, its effect is surpassed by the large amount of carboxylic acids and anhydrides also present in this sample, which are electron withdrawing groups. In a previous work, thermal modification of AC surface chemistry improved its capacity as RM for azo dye chemical and biological reduction (Pereira et al., 2010). This better performance was due to the low concentration of electron withdrawing groups, promoting the exposure of active sites on their basal planes, rich in $\pi$ delocalized electrons. In the biological reduction of NoA here reported, thought that $\mathrm{AC}_{0}$ contains higher amount of oxygen containing groups than $\mathrm{AC}_{\mathrm{H} 2}$, the performance of both as $\mathrm{RM}$ was similar, likely due to their $\mathrm{pH}_{\mathrm{pzc}}$, which is other important characteristic of $\mathrm{CM}$, affecting its surface charge when in solution. At $\mathrm{pH} 7, \mathrm{AC}_{0}$, and $\mathrm{AC}_{\mathrm{H} 2}$ are positively charged whereas $\mathrm{AC}_{\mathrm{HNO}}$ is negatively charged. NoA are ionisable organic compounds, they can exist either as nondissociated or dissociated species in aqueous phase, depending on the solution $\mathrm{pH}$ in relation to their dissociated 

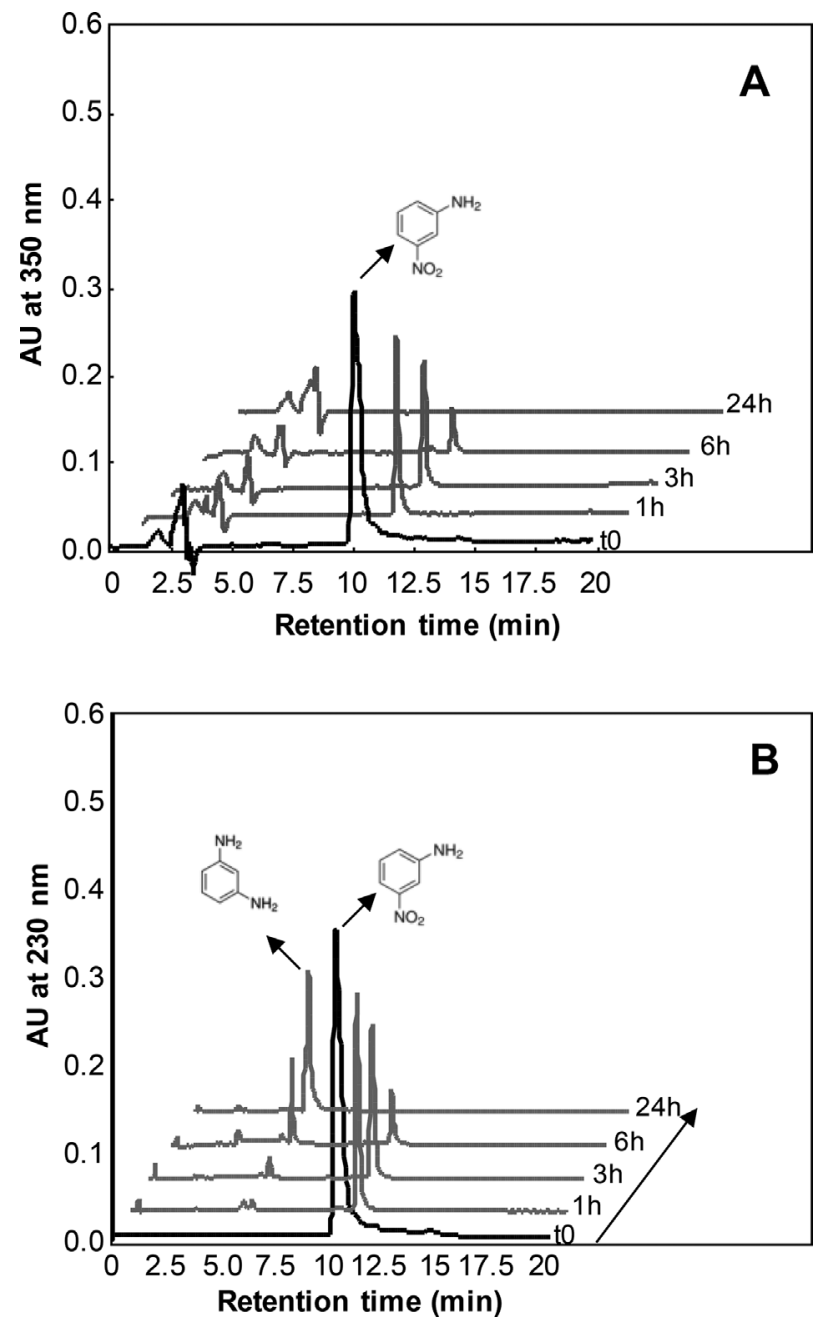

Figure 4. Biological reduction of $m-\mathrm{NoA}$ in the presence of $\mathrm{AC}_{0}$ as monitored by HPLC at the wavelength of $350 \mathrm{~nm}(\mathbf{A})$ and $230 \mathrm{~nm}$ (B).

constants (pKa). Once the pKa of $o-, m$-, and $p$-NoA are $-0.28,2.45$, and 0.98, respectively (Yang et al., 2008), in solution at $\mathrm{pH} \mathrm{7,}$ deprotonation will occur generating the NoA correspondent anions. The electrostatic attraction forces between the positively charged carbons and the negatively charged NoA, will be favorable to the electron shuttling process.

In opposite to our results, Amezquita-Garcia et al. (2013) investigating the effect of AC fibres, original, chemically oxidized and thermally treated, on the chemical $\left(\mathrm{Na}_{2} \mathrm{~S}\right)$ reduction of 4nitrophenol and 3-chloronitrobenzene, have concluded that $\mathrm{AC}$ fibres chemically oxidized are better RM due to the increased number of quinone groups. Controversy, about the primary role of quinone groups on electron shuttle processes is also evident from the work of Liu et al. (2012), who demonstrated that AC, but not AQDS, could accelerate the electron transfer between Geobacter metallireducens and Geobacter, sulfurreducens or Geobacter metallireducens, and Methanosarcina barkeri.

Table SIV at SI, compares the results of this study with other publications on chemical or biological reduction of different
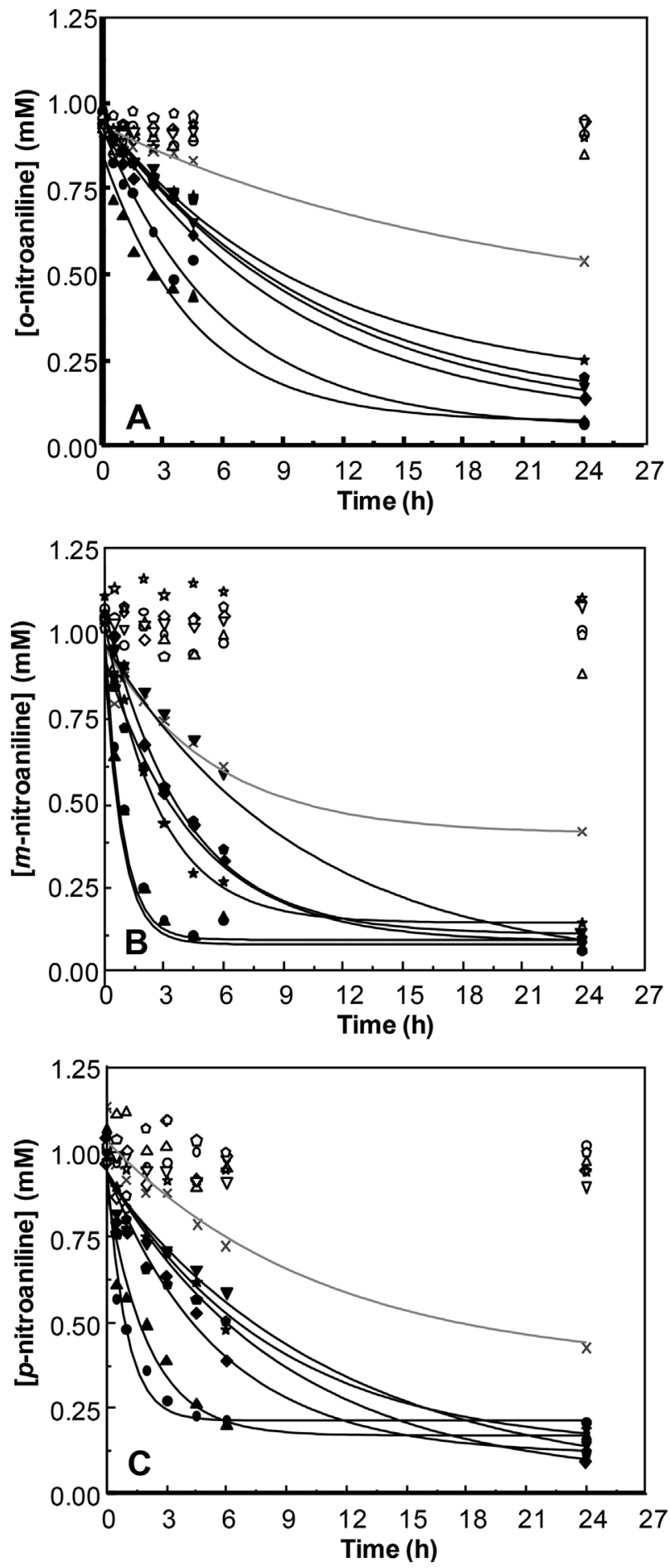

Figure 5. First-order rate curves of $o-\operatorname{NoA}(\mathbf{A}), m-\mathrm{NoA}(\mathbf{B})$, and $p$-NoA biological reduction $(\mathbf{C}) . \times$, no carbon material; $\bullet, \mathrm{AC}_{0} ; \mathbf{\Delta}, \mathrm{AC}_{\mathrm{H} 2} ; \mathrm{AC}_{\mathrm{HNO} 03} \boldsymbol{\star}, \mathrm{CXA} ; \mathrm{CXB}$, and $\boldsymbol{\nabla}$, CNT. Black symbols correspond to the biotic and white symbols to the abiotic assays.

nitrocompounds. It is worth to note that all the previously published reduction rates are much lower than the obtained in our study with $\mathrm{CM}$. Besides, in the previous biological reduction experiments, the process was effective only after long times of biomass acclimation. 
Table I. Effect of $\mathrm{CM}\left(0.1 \mathrm{~g} \mathrm{~L}^{-1}\right)$ on the extent $(\%)$ and rates $\left(\mathrm{d}^{-1}\right)$ of NoA biological reduction $\left(1 \mathrm{mmol} \mathrm{L}^{-1}\right)$

\begin{tabular}{lcccccccc}
\hline & \multicolumn{2}{c}{$o$-NoA } & & \multicolumn{2}{c}{$m$-NoA } & & \multicolumn{2}{c}{$p$-NoA } \\
\cline { 2 - 3 } \cline { 8 - 9 } Condition & $(\%)$ & $\left(\mathrm{h}^{-1}\right)$ & & $(\%)$ & $\left(\mathrm{h}^{-1}\right)$ & & $(\%)$ & $\left(\mathrm{h}^{-1}\right)$ \\
\hline Control & $32 \pm 1$ & $0.07 \pm 0.01$ & & $56 \pm 4$ & $0.26 \pm 0.11$ & & $52 \pm 2$ & $0.14 \pm 0.02$ \\
$\mathrm{AC}_{0}$ & $97 \pm 2$ & $0.15 \pm 0.02$ & & $98 \pm 1$ & $1.14 \pm 0.04$ & & $97 \pm 1$ & $1.05 \pm 0.01$ \\
$\mathrm{AC}_{\mathrm{H} 2}$ & $97 \pm 3$ & $0.22 \pm 0.03$ & & $97 \pm 1$ & $1.12 \pm 0.01$ & & $92 \pm 1$ & $0.99 \pm 0.04$ \\
$\mathrm{AC}_{\mathrm{HNO3}}$ & $94 \pm 1$ & $0.10 \pm 0.03$ & & $95 \pm 1$ & $0.23 \pm 0.01$ & & $94 \pm 1$ & $0.18 \pm 0.01$ \\
$\mathrm{XA}$ & $93 \pm 2$ & $0.10 \pm 0.01$ & & $94 \pm 1$ & $0.22 \pm 0.03$ & & $93 \pm 1$ & $0.14 \pm 0.01$ \\
$\mathrm{XB}$ & $91 \pm 1$ & $0.09 \pm 0.01$ & & $92 \pm 1$ & $0.36 \pm 0.01$ & & $91 \pm 1$ & $0.15 \pm 0.01$ \\
$\mathrm{CNT}$ & $94 \pm 6$ & $0.10 \pm 0.01$ & & $91 \pm 1$ & $0.10 \pm 0.01$ & & $93 \pm 2$ & $0.07 \pm 0.01$ \\
\hline
\end{tabular}

Controls without biomass revealed that adsorption to CM was negligible (see Fig. 5). The values correspond to triplicate assays.

The application of $\mathrm{CM}$ here demonstrated, as increasing the reduction rate of nitrocompounds, may avoid this adaptation period and also decrease the HRT in high rate continuous bioreactors.

\section{CM as Electron Shuttle}

The electron shuttle capacity of $\mathrm{CM}$ was evaluated by measuring the transfer of electrons obtained from biological oxidation of VFA from $\mathrm{AC}_{0}$ to $\mathrm{Fe}^{3+}$, reducing it to $\mathrm{Fe}^{2+}$. In Figure $\mathrm{S} 1$, photography of the magenta complex formed by the reaction of $\mathrm{Fe}^{2+}$ with ferrozine, when reduced $\mathrm{AC}_{0}$ was incubated with $\mathrm{Fe}^{3+}$, is shown. The controls present a slight yellow coloration due to the $\mathrm{Fe}^{3+}$ and also ferrozine color solutions.

In the presence either of 0.1 or $0.5 \mathrm{~g} \mathrm{~L}^{-1}$ of $\mathrm{AC}_{0}$, reduction of $\mathrm{Fe}^{3+}$ was observed and the total amount of $\mathrm{Fe}^{2+}$ was $0.20 \pm 0.05 \mathrm{mM}$ $\mathrm{Fe}^{2+}$, and $0.45 \pm 0.06 \mathrm{Fe}^{2+} \mathrm{mM}$, respectively. In the presence of BES, similar results were obtained: $0.18 \pm 0.05 \mathrm{Fe}^{2+} \mathrm{mM}$ and $0.46 \pm 0.07 \mathrm{Fe}^{2+} \mathrm{mM}$, respectively. In the controls without $\mathrm{AC}_{0}$ or without biomass, no $\mathrm{Fe}^{3+}$ reduction was observed, proving that the reduction of $\mathrm{AC}_{0}$ occurs and consequently reduction of final electron acceptors $\left(\mathrm{Fe}^{3+}\right.$, azo dyes, NoA, etc). Ideally, the redox potential of RM should be in between those of the two reactions, oxidation of a substrate, and reduction of the final electron acceptor

AC

Pereira et al.
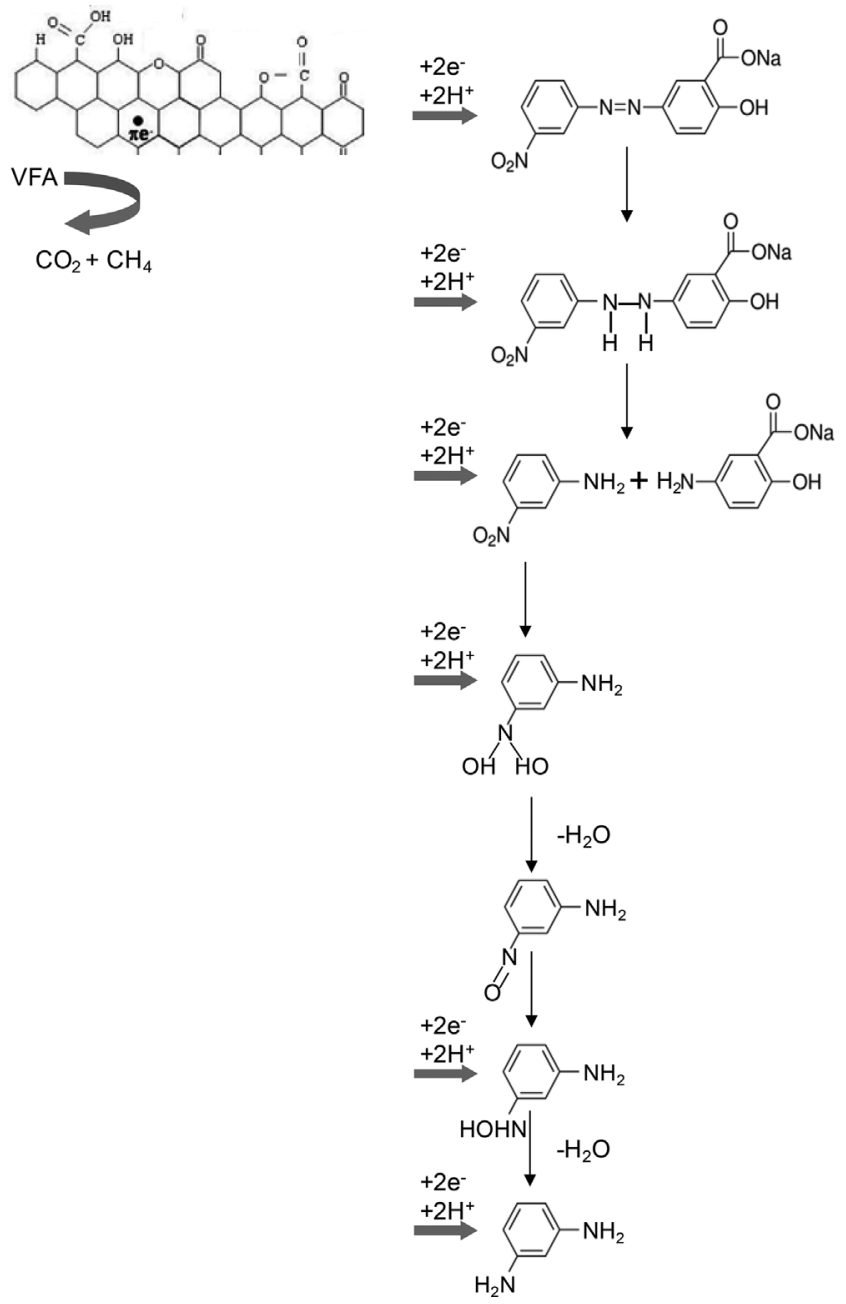

Figure 6. Mechanism of MY1 and $m$-NoA biological reduction with VFA as electron donor, in the presence of $\mathrm{AC}_{0}$. 
(Van der Zee and Cervantes, 2009). However, the efficiency of RM also depends on the activation energy of its reduction and oxidation, in comparison to that of the non-mediated total reaction, but many times this is not verified and RM with redox potentials lower than the primary electron donor or higher than the terminal electron acceptor may also be effective. The different experimental conditions such as $\mathrm{pH}$, temperature, etc) also affect the catalytic efficiency of RM. Redox potentials around $0.25 \mathrm{~V}$ versus $\mathrm{Ag} / \mathrm{AgCl}(\mathrm{KCl}, 1 \mathrm{M})$ are generally ascribed to the hydroquinone/quinone redox couple, but it has been recently demonstrated that pyrones, carbonyls or phenols can also give rise to faradaic reactions in the same potential range (Enterría et al., 2015). Raymundo-Piñero et al. (2006) refer values above $0.4 \mathrm{~V}$ versus $\mathrm{Hg} / \mathrm{Hg}_{2} \mathrm{SO}_{4}$, which may even reach $-0.1 \mathrm{~V}$. RM with more negative redox potentials are, generally, more effective, due to the high concentration of reduced species, which will be available to promote the reduction of the pollutant. The couple $\mathrm{Fe}^{3+/} \mathrm{Fe}^{2+}$ has a high redox potential, of $+0.770 \mathrm{mV}$, and so the electron shuttle from VFA oxidation to the $\mathrm{Fe}^{3+}$ is more difficult to occur that via CM. Dyes and aromatic amines have high redox potentials as well, which also depend on many factors and different values have been reported for the same compound (Van der Zee and Cervantes, 2009).

The results suggest that bacteria are capable of utilizing $\mathrm{CM}$ as a terminal electron to support the oxidation of VFA. The electron shuttle from VFA to $\mathrm{AC}_{0}$ and $\mathrm{AC}_{\mathrm{H} 2}$, initial step, is favored by the fact that at the neutral conditions of the assay, VFA are negatively ionized and $\mathrm{AC}_{0}$ and $\mathrm{AC}_{\mathrm{H} 2}$ positively ionized, due to having a $\mathrm{pH}_{\mathrm{pzc}}$ above the $\mathrm{pH}$ of the reaction, as explained above. This promotes the electrostatic attraction forces between the positively charged carbons and the negatively charged VFA. In a preliminary experiments done with Acid Orange 10 (AO10) (unpublished data), VFA consumption profiles were measured in the first $24 \mathrm{~h}$, in the presence of $\mathrm{AC}_{0}$ and CNT. In general, acetate and propionate were the preferred electron donors and the effect of $\mathrm{AC}_{0}$ was negligible but the presence of CNT delayed the consumption of acetate as compared to the other assays. The results are shown in Table SV at supplementary material.

A shift in the microbial community is not expected to have occurred, since longer times of incubation, continuous reactors, or successive transfers of active cultures into fresh medium would be necessary. Our study was performed in batch assays, operated only during $24 \mathrm{~h}$, and the increase in the reduction rates was immediately observed in the presence of materials, as for example with total reduction of $m$-NoA in the first $3 \mathrm{~h}$ of reaction (Fig. 4B). Furthermore, our previous published work (Pereira et al., 2010) reports on the redox capacity of modified $\mathrm{AC}$ on chemical azo dye reduction, due to the electron transfer capacity.

According to the results, the mechanism of electron shuttle from AC to MY1 and to $m$-NoA is proposed (Fig. 6). The cleavage of the azo bond to the corresponding aromatic amines, involves the transfer of four electrons (reducing equivalents) where the VFA are the electron donors and CM the electron shuttles. The resultant $m$ NoA is further reduced to the $p$-Phe, process that involves the transfer of six electrons.

\section{Potential Methanogenic Toxicity of MY1, NoA, 5-ASA, and of the Final Treated Solutions}

The potential methanogenic toxicity effect of the azo dye MY1, the three NoA, the 5-ASA, and TS in the presence of $\mathrm{AC}_{0}$, was evaluated.

The azo dye MY1 presents a severe toxic effect to the consortium.

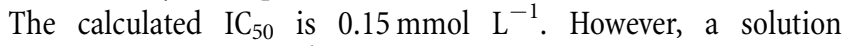
containing $1.0 \mathrm{mmol} \mathrm{L}^{-1}$ of this dye was detoxified by the anaerobic bioprocess in the presence of $\mathrm{CM}$. After the biological reduction with $\mathrm{AC}_{0}$, the $\mathrm{SMA}$ increased from 0 to $(54 \pm 8) \%$ of the maximum obtained in the control assay.

Among the NoA, higher toxic effect was observed for $o$-NoA followed by the $m$-NoA and $p$-NoA and the corresponding $\mathrm{IC}_{50}$ were $0.1,0.3$, and $0.5 \mathrm{mmol} \mathrm{L}^{-1}$, respectively (Fig. 7). The concentrations of the NoA tested in the biological assays $\left(1 \mathrm{mmol} \mathrm{L}^{-1}\right)$ were well above their $\mathrm{IC}_{50}$, which may also explain the low extent of reduction in the absence of $\mathrm{CM}$.

When assessing the methanogenic toxicity potential of the TS, a significant detoxification was observed (Fig. 7). Solutions at $1 \mathrm{mmol}$ $\mathrm{L}^{-1}$ of NoA completely inhibited the SMA, but $(63 \pm 5) \%,(53 \pm 9)$ $\%$, and $(88 \pm 7) \%$ of maximum SMA was recovered after biological treatment with $\mathrm{AC}_{0}$ of $o, m$, and $p$-NoA, respectively. The results obtained are in accordance with literature reporting that aromatic nitro-substituents are responsible for severe methanogenic toxicity, while correspondent aromatic amines (Phe) present lower toxic effects (Donlon et al., 1995, 1997).

On the other hand, according to our results and based on previous published work by Donlon et al. (1995), the recalcitrant nature of 5-ASA seems to not be related with its toxic effect $\left(\mathrm{IC}_{50}>0.1 \mathrm{mmol} \mathrm{L}^{-1}\right)$.

\section{Conclusions}

By applying different $\mathrm{CM}$ on bioreduction of the azo dye MY1 and of $o^{-}, m-$, and $p$-NoA, the efficiency of the process can be significantly improved. We have also proved that in the presence of $\mathrm{CM}$ the $m$-NoA formed from MY1 biological reduction can

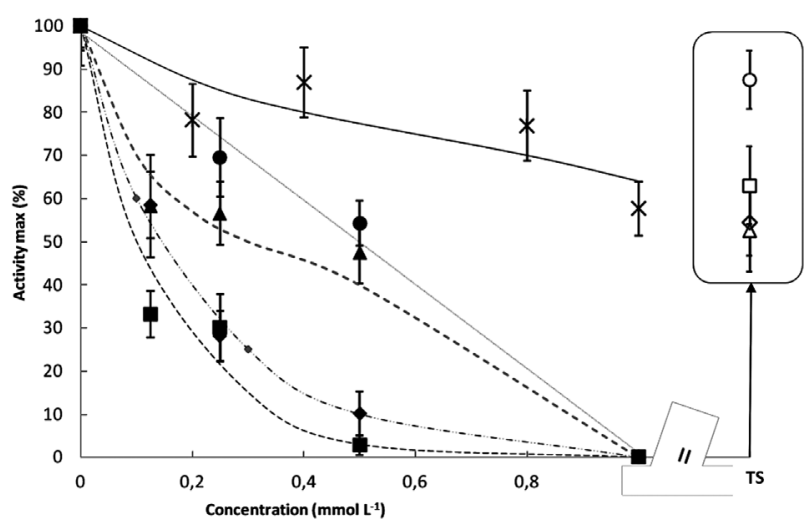

Figure 7. Percentages of specific methanogenic activity, with VFA as substrate, in the presence of increasing concentration of $\boldsymbol{\square}, o$-Phe; $\boldsymbol{\Lambda}, m$-Phe;,$p$-NoA; $\times, 5$ $A S A$, and $\diamond, M Y 1$ and of the final treated solutions (TS), in the presence of $A C_{0}$, containing $1.0 \mathrm{mmol} \mathrm{L}^{-1}$ of $\square, o$-Phe; $\Delta, m$-Phe;,$p$-NoA; and $\diamond$, MY1 
be further reduced into less toxic compound, $m$-Phe, in a short period of time $(\sim 24 \mathrm{~h})$. Rates of NoA biological reduction were dependent on the nitro group position, increasing in the order metha $>$ para $>$ ortho. The surface area of CM had greater effect on NoA biological reduction than the pore sizes, with better results obtained for $\mathrm{AC}_{0}$ and $\mathrm{AC}_{\mathrm{H} 2}$. The $\mathrm{pH}_{\mathrm{pzc}}$ of the materials is also an important factor on reduction reactions, and at $\mathrm{pH} 7$ the electrostatic attraction between the positively charged carbons $\mathrm{AC}_{0}$ and $\mathrm{AC}_{\mathrm{H} 2}$ and the NoA anions favored the electron transfer. The capacity of $\mathrm{CM}$ to act as RM, explaining the higher bioreduction rates, was also proved by measuring the abiotic transfer of electrons from biological oxidation of VFA to $\mathrm{AC}_{0}$ and from reduced $\mathrm{AC}_{0}$ to $\mathrm{Fe}^{3+}$.

The high extent of reduction in the presence of microporous $\mathrm{CM}$, even when compounds are present at toxic levels to the methanogenic consortium and the detoxification obtained with the mediated treatment, up to $88 \%$ for NoA and $54 \%$ for MY1, demonstrate the effectiveness of the process and their promising application in continuous high rate bioreactors.

R. Pereira holds a fellowship (SFRH/BD/72388/2010) from Fundeão para a Ciência e Tecnologia (FCT). The authors thank the FCT Strategic UID/BIO/ 04469/2013 and exploratory EXPL/AAG-TEC/0898/2013 projects.

\section{References}

Amezquita-Garcia HJ, Razo-Flores E, Cervantes FJ, Rangel-Mendez JR. 2013. Activated carbon fibers as redox mediators for the increased reduction of nitroaromatics. Carbon 55:276-284.

Carabineiro SAC, Pereira MFR, Pereira JN, Caparros C, Sencadas V, Lanceros-Mendez S. 2011. Effect of the carbon nanotube surface characteristics on the conductivity and dielectric constant of carbon nanotube/poly(vinylidene fluoride) composites. Nanoscale Res Lett 6:302-306.

Cervantes FJ, Van der Zee FP, Lettinga G, Field JA. 2001. Enhanced decolourization of acid 0 range 7 in a continuous UASB reactor with quinones as redox mediators. Water Sci Technol 44:123-128.

Chung KT, Kirkovsky L, Kirkovsky A, Purcell WP. 1997. Review of mutagenicity of monocyclic aromatic amines: Quantitative structure-activity relationships. Mut Res 387:1-16.

Chung KT. 2000. Mutagenicity and carcinogenicity of aromatic amines metabolically produced from azo dyes. Environ Carcino Ecotoxicol Revs 18(1):51-74.

Donlon B, Razo-Flores E, Field J, Lettinga G. 1995. Toxicity of N-substituted aromatics to acetoclastic methanogenic activity in granular sludge. App Environ Microbiol 61:3889-3893.

Donlon B, Razo-Flores E, Luijten M, Swarts H, Lettinga G, Field J. 1997. Detoxification and partial mineralization of the azo dye mordant orange 1 in a continuous upflow anaerobic sludge-blanket reactor. Appl Microbiol Biotechnol 47:83-90.

Enterría M, Pereira MFR, Martins JI, Figueiredo JL. 2015. Hydrothermal functionalization of ordered mesoporous carbons: The effect of boron on supercapacitor performance. Carbon 95:72-83.

Figueiredo JL, Pereira MFR, Freitas MMA, Oráo JJM. 1999. Modification of the surface chemistry of activated carbons. Carbon 37:1379-1389.

Figueiredo JL. 2013. Functionalization of porous carbons for catalytic applications. J Mater Chem A 1:9351-9364.

Fu H, Zhu D. 2013. Graphene oxide-facilitated reduction of nitrobenzene in sulfidecontaining aqueous solutions. Environ Sci Technol 47:4204-4210.

Garrigós MC, Reche F, Marín ML, Jiménez A. 2002. Determination of aromatic amines formed from azo colorants in toy products. J Chromat A 976:309-317.

Gonçalves AG, Figueiredo JL, Óráo JJM, Pereira MFR. 2010. Influence of the surface chemistry of multi-walled carbon nanotubes on their activity as ozonation catalysts. Carbon 48:4369-4381.
Gong W, Liu X, Tao L, Xue W, Fu W, Cheng D. 2014. Reduction of nitrobenzene with sulfides catalyzed by the black carbons from crop-residue ashes. Environ Sci Poll Res 21:6162-6169.

Jbarah AA, Holze R. 2006. A comparative spectroelectrochemical study of the redox electrochemistry of nitroanilines. J Solid State Electrochem 10:360-372.

Kato S, Hashimoto K, Watanabe K. 2012. Methanogenesis facilitated by electric syntrophy via (semi) conductive iron-oxide minerals. Environ Microbiol 14:1646-1654.

Liu F, Rotaru AE, Shrestha PM, Malvankar NS, Nevin KP, Lovley DR. 2012. Promoting direct interspecies electron transfer with activated carbon. Energy Environ Sci 5:8982-8989.

Lovely D, Phillips EJP. 1986. Availability of ferric iron for microbial reduction in bottom sediments of the freshwater tidal Potomac river. Appl Environ Microbiol 52:751-757.

Malca-Mor L, Stark AA. 1982. Mutagenicity and toxicity of carcinogenic and other hydrazine derivatives: Correlation between toxic potency in animals and toxic potency in salmonella typhimurium TA1538. Appl Environ Microbiol 44(4):801-808.

Mezohegyi G, Gonçalves F, Óráo JJM, Fabregat A, Fortuny A, Font J, Bengoa C, Stuber F. 2010. Tailored activated carbons as catalysts in biodegradation of textile azo dyes. Appl Catal B: Environ 94:179-185.

Orge CA, Órño JJM, Pereira MFR. 2012. Carbon xerogels and ceria-carbon xerogel materials as catalysts in the ozonation of organic pollutants. Appl Cat B: Environ 126:22-28.

Pereira L, Pereira R, Pereira MFR, Van der Zee FP, Cervantes FJ, Alves MM. 2010. Thermal modification of activated carbon surface chemistry improves its capacity as redox mediator for azo dye reduction. J Haz Mater 183:931-939.

Pereira RA, Pereira MFR, Alves MM, Pereira L. 2014. Carbon based materials as novel redox mediators for dye wastewater biodegradation. Appl Catal B: Environ 144:713-720.

Raymundo-Piñero E, Leroux F, Béguin F. 2006. A high-performance carbon for supercapacitors obtained by carbonization of a seaweed biopolymer. Adv Mater 18:1877-1882.

Razo-Flores E, Lettinga G, Field JA. 1999. Biotransformation and biodegradation of selected nitroaromatics under anaerobic conditions. Biotechnol Prog 15:358-365.

Sarasa J, Roche MP, Ormad MP, Gimeno E, Puig A, Ovelleiro JL. 1998. Treatment of a wastewater resulting from dyes manufacturing with ozone and chemical coagulation. Water Res 32:2721-2727.

Spain JC. 1995. Biodegradation of nitroaromatic compounds. Ann Rev Microbiol 49:523-555.

Tessonnier JP, Rosenthal D, Hansen TW, Hess C, Schuster ME, Blume R, Girgsdies F, Pfänder N, Timpe O, Su DS, Schlögl R. 2009. Analysis of the structure and chemical properties of some commercial carbon nanostructures. Carbon 47(7):1779-1798.

Van der Zee FP, Bouwman RHM, Strik DPBTB, Lettinga G, Field JA. 2001. Application of redox mediators to accelerate the transformation of reactive azo dyes in anaerobic bioreactors. Biotechnol Bioeng 75(6):691-701.

Van der Zee FP, Bisschops IAE, Lettinga G. 2003. Activated carbon as an electron acceptor and redox mediator during the anaerobic biotransformation of azo dyes. Environ Sci Technol 37:402-408.

Van der Zee FP, Cervantes FJ. 2009. Impact and application of electron shuttles on the redox (bio) transformation of contaminants: A review. Biotechnol Adv 27:256-277.

Wang J, Wang D, Liu G, Jin R, Lu H. 2014. Enhanced nitrobenzene biotransformation by graphene-anaerobic sludge composite. J Chem Technol Biotechnol 89:750-755.

Yang K, Wu W, Jing Q, Zhu A. 2008. Aqueous adsorption of aniline, phenol, and their substitutes by multi-walled carbon nanotubes. Environ Sci Technol 42: 7931-7936.

Yu X, Gong W, Liu X, Shi L, Han X, Bao H. 2011. The use of carbon black to catalyze the reduction of nitrobenzenes by sulfides. J Haz Mater 198:340-346.

\section{Supporting Information}

Additional supporting information may be found in the online version of this article at the publisher's web-site. 